\title{
Catechin sublimation pressure and solubility in supercritical carbon dioxide
}

\author{
Felycia Edi Soetaredjo $^{a}$, Suryadi Ismadji ${ }^{\mathrm{b}, * *}$, Maria Yuliana Liauw $^{\mathrm{a}}$, \\ Artik Elisa Angkawijaya ${ }^{a}$, Yi-Hsu Ju ${ }^{\mathrm{a}, *}$ \\ a Department of Chemical Engineering, National Taiwan University of Science and Technology, 43, Sec 4, Keelung Road, Taipei, Taiwan \\ ${ }^{\mathrm{b}}$ Department of Chemical Engineering, Widya Mandala Surabaya Catholic University, Kalijudan 37, Surabaya 60114, Indonesia
}

\section{A R T I C L E I N F O}

\section{Article history:}

Received 7 February 2013

Received in revised form 6 August 2013

Accepted 8 August 2013

Available online 29 August 2013

\section{Keywords:}

(+)-Catechin

Solubility

Sublimation pressure

Density based correlation

\begin{abstract}
A B S T R A C T
Solubility of $(+)$-catechin in SC- $\mathrm{CO}_{2}$ was measured at several temperatures $(313.15,323.15,333.15$ and $343.15 \mathrm{~K}$ ) and pressure in the range of $12-26 \mathrm{MPa}$ using ethanol as the co-solvent ( $5 \mathrm{~mol} . \%)$. The experimental data were used for the correlation of density dependent solute solubility parameters. The equations of Chrastil, del Valle and Aguilera, Adachi and Lu, González, and Méndez-Santiago and Tejawere fitted very well for the solubility of (+)-catechin. The rate of mass loss of (+)-catechin showed that its sublimation pressure is very low, an indication of the stability of the compound. Thermogravimetric analysis was used to determine the sublimation pressure.
\end{abstract}

(c) 2013 Elsevier B.V. All rights reserved.

\section{Introduction}

Supercritical fluid extraction is superior to conventional extraction techniques because the absence of organic solvents and operates at lower temperature which reduces the incidence of degradation of the product and does not require subsequent purification steps. Supercritical fluids are attractive solvents because they have diffusivities between those of gases and liquids, densities much greater than those of typical gases and slightly less than those of organic liquids, and viscosities comparable to gasses [1]. Supercritical carbon dioxide $\left(\mathrm{SC}-\mathrm{CO}_{2}\right)$ is commonly used for most of the applications because it has a relatively low critical pressure (7.374 MPa) and critical temperature $(304.12 \mathrm{~K})$. The other reasons are it is non-toxic, non-flammable, and non-explosive; and it is spontaneously separated from the extracted compounds by reducing the pressure and/or the temperature.

The knowledge of solubility of a compound in $\mathrm{SC}-\mathrm{CO}_{2}$ is crucial for evaluating the feasibility of supercritical separation of the compound and for establishing optimum operation condition. The solubility of a solid in $\mathrm{SC}-\mathrm{CO}_{2}$ depends on its polarity. $\mathrm{SC}-\mathrm{CO}_{2}$ is not a good solvent for polar organic compounds due to its low of polarity and its lack of specific solvent-solute interactions. The addition

\footnotetext{
* Corresponding author. Tel.: +88622737 6611; fax: +8862 27376644 .

** Corresponding author. Tel.: +62 31 3891264; fax: +62 313891267.

E-mail addresses: suryadiismadji@yahoo.com (S. Ismadji), yhju@mail.ntust.edu.tw (Y.-H. Ju).
}

of a small amount of proper co-solvent to $\mathrm{SC}-\mathrm{CO}_{2}$ can increase its solvent power dramatically. The concentration of added co-solvent should be less than $15 \mathrm{~mol}$ \% [2,3]. Co-solvent is usually one of the common liquid solvents such as benzene, methylene chloride, carbon tetrachloride, hexane, acetone, methanol, ethanol, toluene and water [1,3-8]. The role of co-solvent has been limited in the area of food and pharmaceutical because of the toxic nature of most organic solvents and the associated problem of removing cosolvent residue completely from the processed material. Among organic solvents, ethanol is appropriate because it is polar and permitted in food industries.

Catechin ((2R,3S)-2-(3,4-Dihydroxyphenyl)-3,4-dihydro$1(2 \mathrm{H})$-benzopyran-3,5,7-triol) is a phytochemicals in the group of flavonoids. It is abundantly in various plants such as tea [9-11], grape [12-15] and cocoa [16]. Catechin is also found in the sago (Metroxylon sago) pith. During sago starch extraction, catechin is oxidized by latent polyphenol oxidase and the color of the wastewater become dark brown with strong odor [17]. Since catechin has many benefits on health especially as an antioxidant, the separation of catechin will not only reduce water pollution but also obtain valuable compound.

Catechin solubility in $\mathrm{SC}-\mathrm{CO}_{2}$ was studied by Berna et al. using ethanol (5-30 mol.\%) as the co-solvent operated at $313 \mathrm{~K}$ and 8-12 MPa [4]. TheSC- $\mathrm{CO}_{2}$ extraction of catechin without using cosolvent was not feasible since only trace amount was extracted. However, the presence of a high amount of ethanol in $\mathrm{SC}-\mathrm{CO}_{2}$ ( $\geq 15 \mathrm{~mol} . \%$ ) will change the supercritical condition to subcritical since ethanol has a high critical temperature of $513.9 \mathrm{~K}$ 
Table 1

Specification of chemicals used in this study.

\begin{tabular}{|c|c|c|c|c|}
\hline Chemical name & Source & Initial mass fraction purity & Purification method & Final fraction purity \\
\hline$(+)$-Catechin hydrate & Sigma-Aldrich & $\geq 98$ wt.\% & None & $\geq 98$ wt.\% \\
\hline Caffeine & Sigma-Aldrich & $\geq 99.9$ wt. $\%$ & $\begin{array}{l}\text { Recrystallized twice and } \\
\text { tempered at } 110^{\circ} \mathrm{C} \text { to obtain } \\
\text { the } \beta \text {-anhydrous phase (form } \\
\text { II) as described by Pinto and } \\
\text { Diogo[26]. }\end{array}$ & $\bar{\beta}$-Anhydrous caffeine $\geq 99.9$ wt.\% \\
\hline Ethanol & Merck, Germany & $\geq 99.9$ wt.\% & None & $\geq 99.9$ wt. $\%$ \\
\hline Liquid $\mathrm{CO}_{2}$ & Aneka Gas Pty. Ltd., Indonesia & $\overline{\text { Food }}$ grade $\geq 99.99 \mathrm{wt} . \%$ & None & $\geq 99.99$ wt.\% \\
\hline
\end{tabular}

$[2,3,18,19]$. In this work, catechin solubility in $\mathrm{SC}-\mathrm{CO}_{2}$ was investigated in a wider range of pressure and temperature (12-26 MPa and $313.15-343.15 \mathrm{~K}$, respectively) than the published data. In order to maintain the supercritical condition of carbon dioxide, the cosolvent ethanol concentration was kept at $5 \mathrm{~mol} . \%$ [20].

The solubility profile of a compound in $\mathrm{SC}-\mathrm{CO}_{2}$ is influenced by its density as well as pressure and temperature. Density based correlation was developed based on the observation that the logarithm of the solubility is linearly dependent on the density [21,22]. Chrastil [23] was the first in developing a semi-empirical solubility correlation based on this approach, taking into account the dependence of solubility upon temperature. Although the Chrastil model is limited to low solubility and temperature, it has the advantage of avoiding the difficulty of determination of equation of states parameters, especially for high molecular mass solutes [24]. Another density based correlation was proposed by MéndezSantiago and Teja (MST) [25] for ternary co-solvent systems by taking account of sublimation pressure of the solute. The objective of this study was to measure the sublimation pressure and the solubility of catechin in $\mathrm{SC}-\mathrm{CO}_{2}$ with ethanol as the co-solvent and then correlated the data using density based model.

\section{Experimental}

\subsection{Materials}

(+)-Catechin and caffeine were obtained from Sigma Aldrich (Singapore). (+)-catechin was used without any further treatment. Analytical grade ethanol was supplied by Merck (Darmstadt, Germany) and used as a co-solvent in $\mathrm{SC}-\mathrm{CO}_{2}$ and a solvent to collect extract for further analysis. Food grade carbon dioxide was supplied as liquid $\mathrm{CO}_{2}$ by Aneka Gas Pty. Ltd., Indonesia. Table 1 shows the specification of chemicals used in this study.

\subsection{Sublimation pressure}

Thermogravimetric analysis (TGA) is usually used to study the thermal stability of a material. In addition, it can be used to study its phase transitions such as sublimation and the related properties such as vaporpressure [27-29]. TGA provides a fast and reliable method to study a number of compounds that are thermally stable up to their melting point at ambient pressure [27,29]. Using this method, the evaporation rate of a compound determined under isothermal conditions is directly related to its vapor pressure [27-31].

In this study, the rate of sublimation was measured using a highly sensitive microbalance in TGA (Perkin Elmer Diamond TG/DTA). The measurements were carried out in dynamic nitrogen atmosphere with a flow rate of $40 \mathrm{ml} / \mathrm{min}$. The amount of the sample was kept low (approximately $3 \mathrm{mg}$ ) and it should fully covered the bottom of the platinum pan ( $\varnothing 5 \mathrm{~mm}$ ) in order to minimize thermal gradients. The experiments were conducted at a temperature range from 423 to $443 \mathrm{~K}( \pm 0.01 \mathrm{~K})$ under isothermal conditions. The heating temperature was rising linearly at $40 \mathrm{~K} / \mathrm{min}$ from ambient to the targeted temperature and then maintained at that temperature. Mass loss rates $(d m / d t)$ were determined from a region where the temperature was constant.

Analysis of the gravimetric data is based on the mass loss rate of a substance that is related to its vapor pressure and can be expressed by the Langmuir equation

$P=\frac{\sqrt{2 \pi R}}{\alpha} \times \frac{d m}{d t} \times \sqrt{\frac{T}{M}}$

where $P$ is the vapor pressure, $R$ is the universal gas constant, $\alpha$ is the vaporizations coefficient (usually assumed to be 1 in vacuum condition), $d m / d t$ is the rate of mass loss with respect to time, $T$ is the absolute temperature and $M$ is the molecular weight of the substance in the vapor phase. In the case of a material volatilizing into a flowing gas stream at $1 \mathrm{~atm}, \alpha$ cannot be assumed as unity. The value of $\alpha$ is sample independent and can be evaluated by calibration with substances of known vapor pressures. In this study the calibration was conducted using $\beta$-anhydrous caffeine. The vaporization rate of caffeine was determined between 423 and $433 \mathrm{~K}$ (the same temperature range used for catechin) [29]. The linear logarithmic relationship between vapor pressure and mass loss rate [29] is determined as:

$\ln P=a \times \ln \left(\frac{d m}{d t}\right)+b$

$a$ and $b$ are constants specific for the instrument and for the experimental procedures as described above. Estimating from the plot with $R^{2}=0.99$, the value of $a$ and $b$ are 1.135 and 0.255 , respectively. These values are independent of material and temperature range but depend on the equipment and the sample crucible [29,30].

\subsection{Solubility of catechin in $\mathrm{SC}-\mathrm{CO}_{2}$}

The solubility of catechin in $\mathrm{SC}-\mathrm{CO}_{2}$ was performed in a static system. The system includes a $50 \mathrm{ml}$ equilibration column (Swagelok, USA), a high pressure pump (Eldex AA-100-S-2-CE, USA) and pressure transducer (Druck PTX 611, USA) with a digital process indicator (Druck DPI 280, USA) which gives pressure measurement uncertainties of $\pm 0.01 \mathrm{MPa}$. A heating chamber (Oven Memmert, Germany) was used to control temperature to within $\pm 1 \mathrm{~K}$. The maximum working pressure and temperature of the system are $40 \mathrm{MPa}$ and $373.15 \mathrm{~K}$, respectively. All fitting and tubing used in the system were made of stainless steel 316 (Swagelok, USA).

A known mass of (+)-catechin (100 mg) and ethanol (5 mol.\%) were added in a sample holder in the equilibration column. The heating chamber was heated to a desired temperature (313.15, $323.15,333.15$, or $343.15 \mathrm{~K}$ ). Liquid $\mathrm{CO}_{2}$ was subsequently pumped into the system using a high pressure pump until a targeted pressure was achieved (12-26 MPa). After equilibrium condition was achieved in $4 \mathrm{~h}$, the sampling tube $(1 \mathrm{ml})$ was disconnected from the system. The sample in the sampling tube was released, and the $\mathrm{CO}_{2}$ containing catechin flowed into a collector containing a known amount of ethanol while the $\mathrm{CO}_{2}$ was released into the air. At least 
Table 2

Mass loss rate and vapor pressure of (+)-catechin from TGA measurements.

\begin{tabular}{lcc}
\hline Temperature $(\mathrm{K})$ & $\frac{d m}{d t}\left(\frac{\mu g}{\mathrm{~min}}\right)$ & $P(\mathrm{~Pa})$ \\
\hline 423 & 0.3 & 0.3 \\
428 & 0.8 & 0.9 \\
433 & 1.4 & 1.8 \\
438 & 2.5 & 3.6 \\
443 & 3.8 & 5.8 \\
\hline
\end{tabular}

three replications of trails were carried out for every set of temperature and pressure. The equilibrium composition was represented by average of the three replications. The determination of catechin was based on the method of Zuo et al. [32] by using a HPLC (JASCO HPLC PU-2089 plus) with a UV-vis detector (UV-2077 plus).

\section{Results and discussion}

\subsection{Sublimation pressure of catechin}

The mass loss rates and vapor pressure of (+)-catechin at different temperatures are shown in Table 2. The vapor pressure of $(+)$-catechin was calculated using Eq. (2). The sublimation kinetics of $(+)$-catechin was calculated using the Arrhenius equation [29]:

$\ln \frac{d m}{d t}=\ln A-\frac{E_{\mathrm{a}}}{R T}$

where $d m / d t$ is the mass loss rate of catechin, $A$ is the preexponential factor, $E_{\mathrm{a}}$ is the activation energy, $R$ is the universal gas constant and $T$ is the absolute temperature. From the plot of $1 / T$ versus $\ln (d m / d t)$ as shown in Fig. $1\left(R^{2}=0.98\right)$, the activation energy and the pre-exponential factor was determined as $194.43 \mathrm{~kJ} / \mathrm{mol}$ and 54.238 , respectively.

Clausius-Clapeyron equation describes the temperature dependence of the vapor pressure:

$\ln P=-\frac{\Delta H}{R}\left(\frac{1}{T}\right)+\frac{\Delta S}{R}$

where $\Delta H$ is the standard enthalpy change of sublimation and $\Delta S$ is the standard entropy of sublimation. (+)-Catechin sublimes without decomposition in the temperature range used in this study since (+)-catechin decomposes above $1108 \mathrm{~K}$ (Fig. 2). The enthalpy of sublimation and entropy were determined from the plot of $\ln P$ versus $1 / T\left(R^{2}=0.98\right)$ in Fig. 3 and their values are $220.74 \mathrm{~kJ} / \mathrm{mol}$ and $514.05 \mathrm{~J} / \mathrm{mol} \mathrm{K}$, respectively.

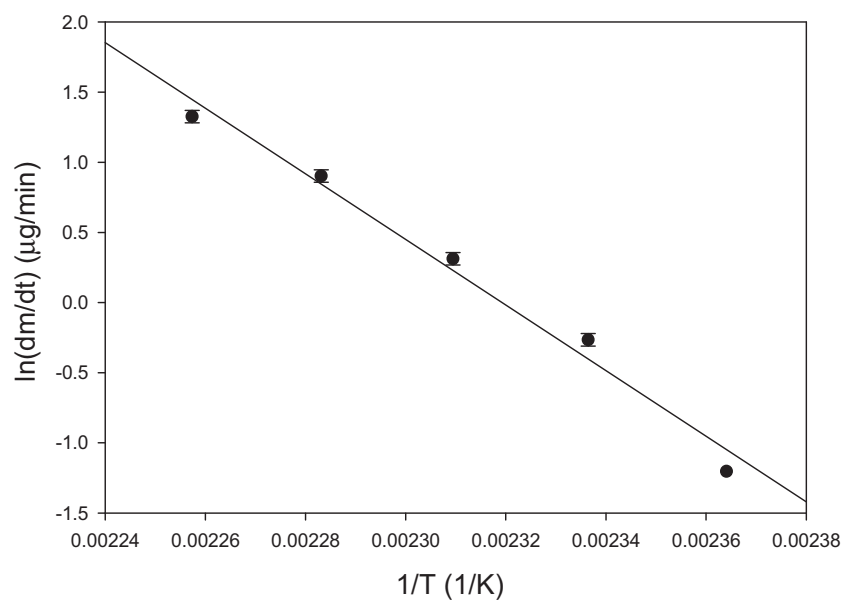

Fig. 1. The plot of $1 / T$ versus $\ln (d m / d t)$ for determining the Arrhenius parameters.

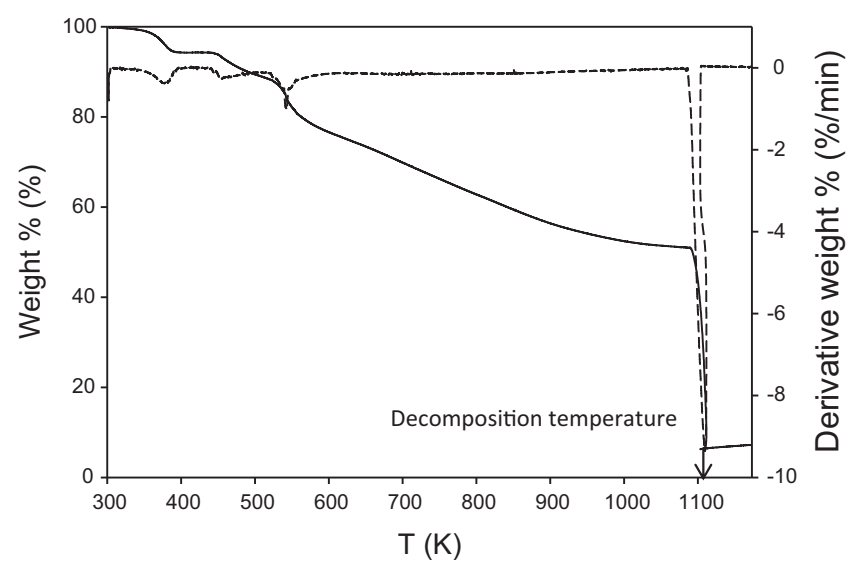

Fig. 2. Thermogravimetric curves of (+)-catechin. Weight loss (-). Derivative of weight loss (-).

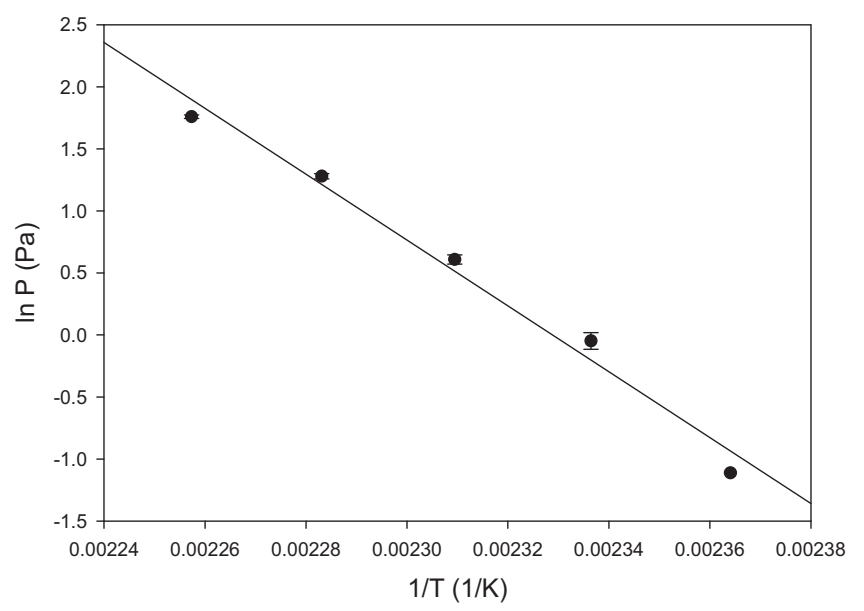

Fig. 3. The plot of $1 / T$ versus $\ln P$ for determining the Clausius-Clapeyron parameters.

\subsection{Solubility of catechin in $\mathrm{SC}-\mathrm{CO}_{2}$}

Pressure and temperature of SC- $\mathrm{CO}_{2}$ determine its effectiveness as a solvent through affecting its density. The density of $\mathrm{SC}-\mathrm{CO}_{2}$ at various pressures and temperatures were calculated using the Stryjek and Vera modification of the Peng-Robinson equation of state [33]. In the measuring of solubility of catechin in $\mathrm{SC}-\mathrm{CO}_{2}$, insignificant increase of catechin concentration in $\mathrm{CO}_{2}$ was observed after $3 \mathrm{~h}$ as shown in Fig. 4. The calculated density of $\mathrm{SC}-\mathrm{CO}_{2}$ and the

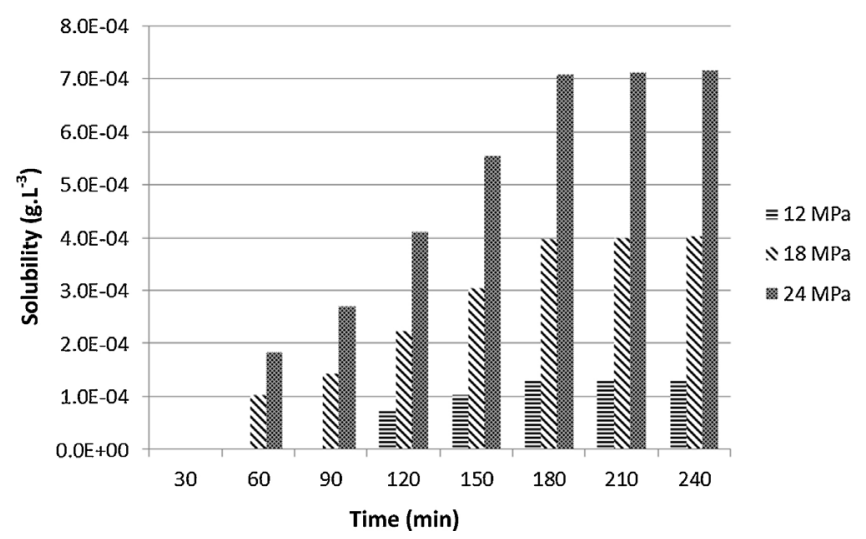

Fig. 4. Solubility of (+)-catechin in $\mathrm{SC}-\mathrm{CO}_{2}$ versus time at various pressures. 


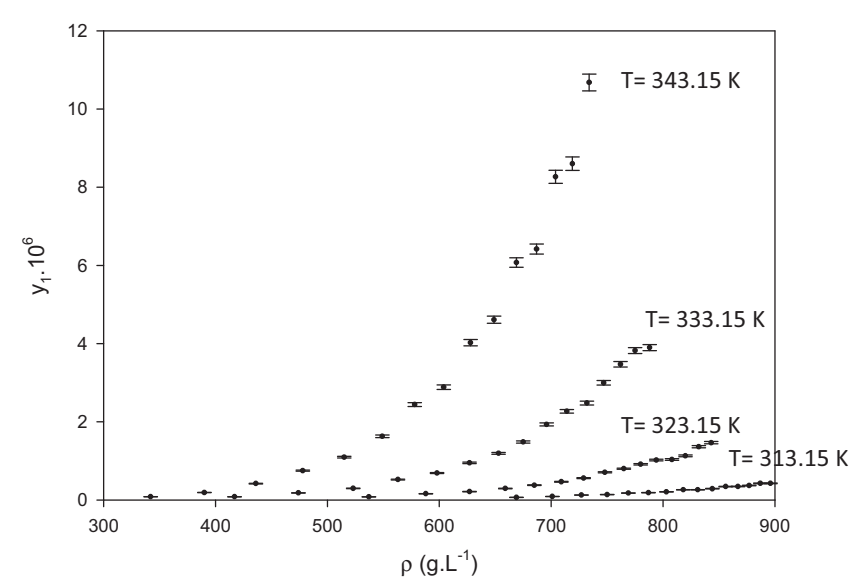

Fig. 5. Solubility of (+)-catechin versus density of $\mathrm{SC}-\mathrm{CO}_{2}$ at various temperature.

measured solubility of $(+)$-catechin in $\mathrm{SC}-\mathrm{CO}_{2}$ are presented in Table 3 and the solubility of (+)-catechin in $\mathrm{SC}-\mathrm{CO}_{2}$ is shown graphically in Fig. 5. At constant temperature, the density of $\mathrm{SC}-\mathrm{CO}_{2}$ increases with increasing pressure which result in an increase in the solubility of (+)-catechin in $\mathrm{SC}-\mathrm{CO}_{2}$. As the temperature increases at constant pressure, the viscosity and diffusivity of $\mathrm{SC}-\mathrm{CO}_{2}$ increase which cause the solubility of $(+)$-catechin in $\mathrm{SC}-\mathrm{CO}_{2}$ to increase even though the density of $\mathrm{SC}-\mathrm{CO}_{2}$ decreases.

Several correlations have already been developed to correlate and extrapolate solubility data to various pressures and temperatures. Some of these correlations are empirical, while the others have fundamental basis. However, these correlations still need one or more adjustable fitting parameters, therefore, experimental data are still needed. Semi-empirical solubility correlation was developed based on the observation that the logarithm of the solubility is linearly dependent on the density. This approach does not require knowledge of solute properties and was found to be very successful in correlating existing solubility data [22]. Chrastil [23] was the first in developing such a correlation by assuming that molecules of the solute associate with the molecules of the gas in equilibrium with solvato complex, $A+k B \leftrightarrow A B_{k}$, so that the equilibrium concentration can be calculated from the law mass action. The semi-empirical Chrastil equation has the form

$y_{1}=\rho^{k} \exp \left(\frac{a}{T}+b\right)$

where $y_{1}$ is the concentration of the solute in gas (mole fraction), $\rho$ is the density of gas, $k$ is an association number, $T$ is temperature, $a$ and $b$ are parameters. It was found that in most cases the solvato complex was not stoichiometric, so that the association constant $k$ expresses an average equilibrium association number, which is a characteristic constant for a given pair of gas and solute.

There are a number of modified Chrastil equations available. Del Valle and Aguilera [34] proposed an empirical modification on the Chrastil equation in the form of

$y_{1}=\rho^{k^{\prime}} \exp \left(b^{\prime}+\frac{a^{\prime}}{T}+\frac{d}{T^{2}}\right)$

to compensate for the variation of heat of vaporization of solute with temperature. In Chrastil equation, the total reaction heat was the sum of heat of solvation and heat of vaporization of solute presented in the parameter of $a(a=\Delta H / R)$. In del Valle and Aguilera equation the variation of enthalpy of vaporization with temperature is $\Delta H(T)=R\left(a^{\prime}+2 d / T\right)$.

Adachi and Lu $[35,36]$ proposed that the association number (referred to as $\kappa$ in the Chrastil equation) is the exponent of the density and shows the dependence of the solubility on the density. According to Adachi and Lu, if Chrastil equation fitting is not as

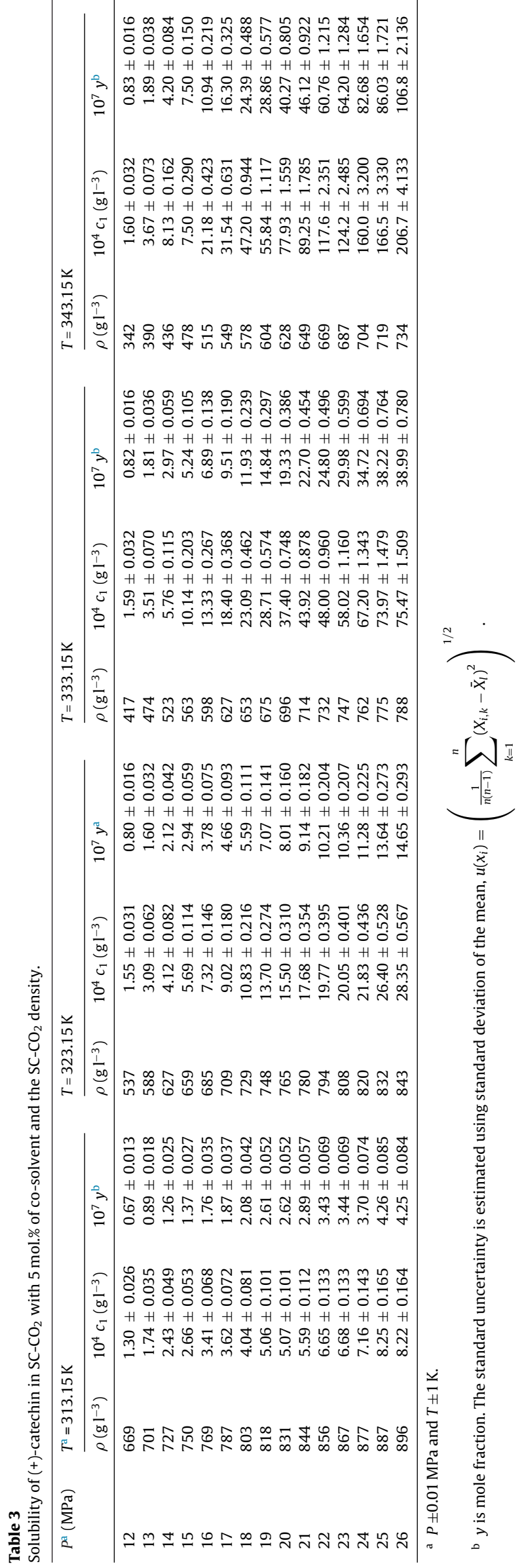




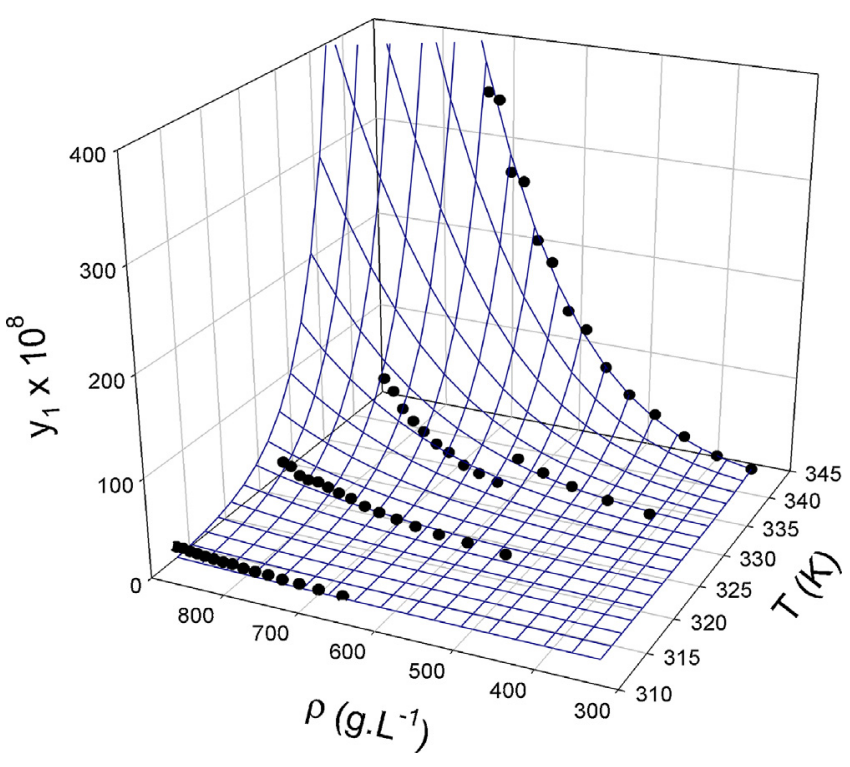

Fig. 6. Chrastil correlation (wire mesh) and experimental solubility data of (+)catechin $(\bullet)$.

good as expected, then the first trial is that the association number should be varied linearly with density $\left(k=e_{0}+e_{1} \rho_{1}\right.$, where $e_{0}$ and $e_{1}$ are constant). And in the extreme case, the association number can be in a quadratic $\left(k=e_{0}+e_{1} \rho_{1}+e_{2} \rho_{1}^{2}\right.$, where $e_{0}, e_{1}$ and $e_{2}$ are constant).

González et al. [24] derived an equation for solubilization of a solute in $\mathrm{SC}-\mathrm{CO}_{2}$ modified with co-solvent based on Chrastil equation. They assumed that each molecule of solute (A) associates with $k$ molecules of carbon dioxide (B) and $\gamma$ molecules of co-solvent (C). González equation has the form

$y_{1}=\rho^{k} m^{\gamma} \exp \left(\frac{a}{T}+b\right)$

where $a=\Delta H_{\text {total }} / R, b=q-k \ln M_{\mathrm{B}}-k \ln \gamma-k \ln M_{\mathrm{c}}+\ln \left(M_{\mathrm{A}}+\right.$ $\left.k M_{\mathrm{B}}+\gamma M_{\mathrm{C}}\right)=$ constant, $k$ is the association number of carbon dioxide and $\gamma$ is the association number of co-solvent.

The estimation of constants for the semi-empirical density based correlations (Chrastil, del Valle and Aguilera, Adachi and Lu and González) was done using multivariable non-linear regression analysis. The quality of all data correlations was quantified by the sum of squared errors (SSE), defined as follows:

$\mathrm{SSE}=\left(\frac{\left(\sum y_{1(\mathrm{exp})}-y_{1(\mathrm{cal})}\right)^{2}}{N}\right)^{1 / 2}$

where $y_{1(\exp )}$ is the actual solubility of (+)-catechin in $\mathrm{SC}-\mathrm{CO}_{2}, y_{1(\mathrm{cal})}$ is the calculated solubility, and $N$ is the number of experimental data. The multivariable non-linear regression technique involved an iterative curve fitting procedure. An initial estimation for each parameter was provided, and then calculation of a point by point sum of squares (Eq. (8)) for each iteration was conducted until convergence criteria were fulfilled.

Figs. 6-9 show the results of multivariable non-linear regression calculations for the correlation of Chrastil, del Valle and Aguilera, Adachi and Lu, and González, respectively. Table 4 summarizes the constants resulted from the calculations. The association number obtained by Chrastil and del Valle and Aguilera correlation is the sum of association number of carbon dioxide and ethanol which indicates that each catechin molecule associates with 5.3 molecules of carbon dioxide and ethanol. The association number obtained from González correlation shows that each catechin molecule associates with 3.37 molecules of carbon dioxide and 1.97

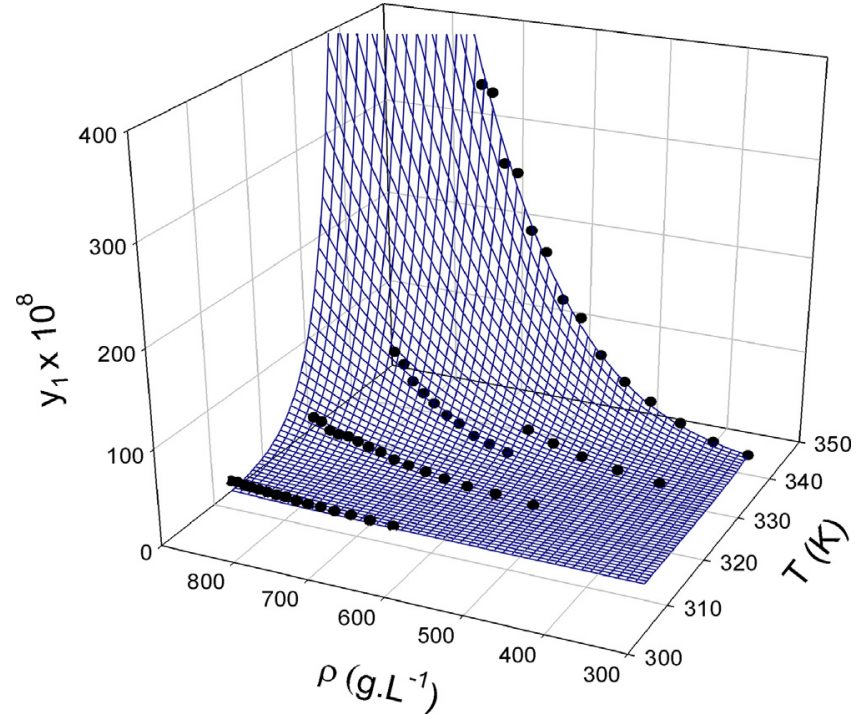

Fig. 7. del Valle and Aguilera correlation (wire mesh) and experimental solubility data of $(+)$-catechin $(\bullet)$.

of co-solvent ethanol molecule. The associate number in Adachi and Lu correlation is presented as a linear function of density (Table 4). The constant $a$ is directly related to the enthalpy of solvation and vaporization ( $a=\Delta H / R$ ); except for the correlation of del Valle and Aguilera. The value of total enthalpy calculated from del Valle and Aguilera equation is similar to the other correlations (Table 4). This shows that the variation of temperature in the range of these experiments is not affecting the enthalpy of vaporization.

Méndez-Santiago and Teja [25] proposed a semi-empirical correlation based on the theory of dilute solution. Méndez-Santiago and Teja equation is a density based model and requires knowledge of the sublimation pressure of the solid solute. This equation demonstrates that the solubility data for a binary system over a significant range of temperatures and pressures can be plotted on a single straight line:

$T \ln E=A+B \rho$

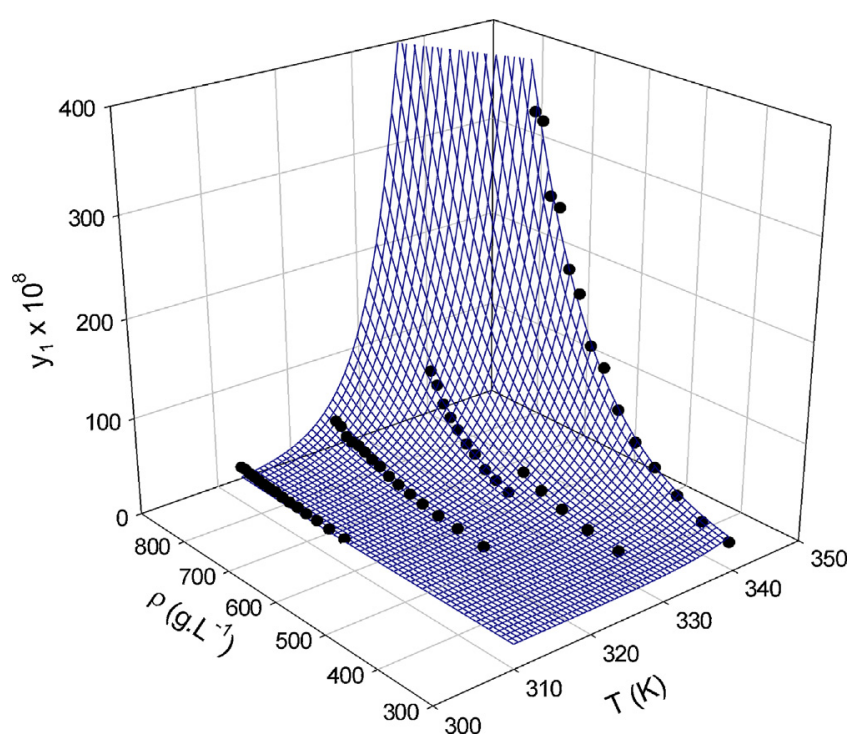

Fig. 8. Adachi and Lu correlation (wire mesh) and experimental solubility data of $(+)$-catechin $(\bullet)$ 
Table 4

Semi-empirical density based correlation constants.

\begin{tabular}{|c|c|c|c|c|c|c|c|}
\hline Model & $k$ & $a$ & $b$ & $d$ & $\gamma$ & $\Delta H(\mathrm{~kJ} / \mathrm{mole})$ & SSE \\
\hline Chrastil & 5.35 & $-21,424.35$ & 14.7716 & - & - & -178.12 & 0.142 \\
\hline Del Valle and Aguilera & 5.34 & $-22,315.73$ & 16.0853 & $151,185.56$ & - & $-(177.50$ to 178.20$)$ & 0.141 \\
\hline Adachi and Lu & $1.9049+0.0007 \rho$ & $-21,725.75$ & 34.7191 & - & - & -180.63 & 0.140 \\
\hline González & 3.37 & $-21,424.35$ & 24.4236 & - & 1.97 & -178.12 & 0.143 \\
\hline
\end{tabular}

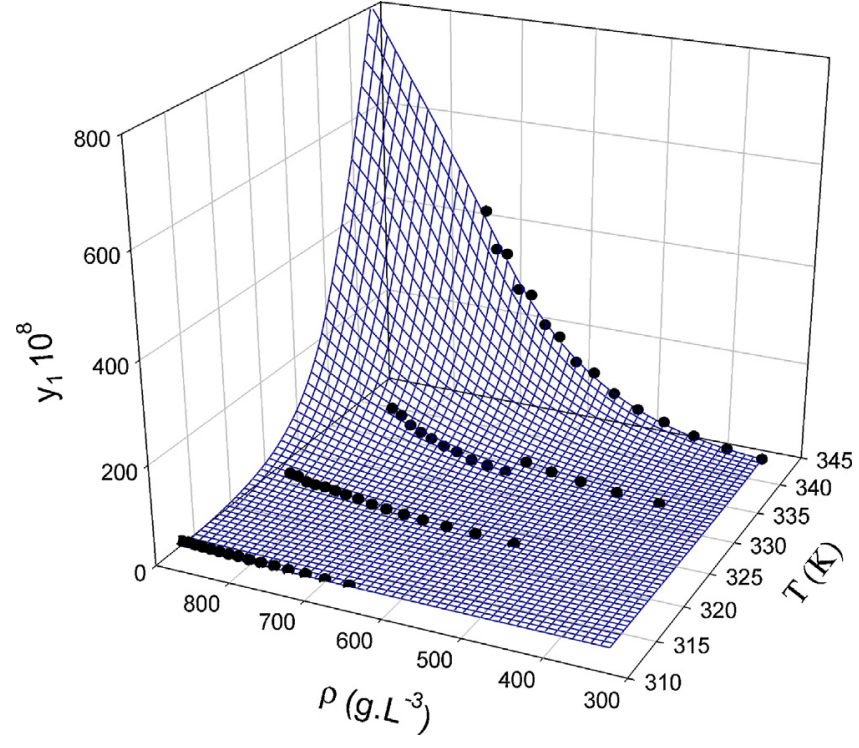

Fig. 9. González correlation (wire mesh) and experimental solubility data of (+)catechin $(\bullet)$.

where $E=y_{1} P / P_{1}^{\text {sub }}$ is the enhancement factor. $P$ is pressure, $P_{1}^{\text {sub }}$ is sublimation pressure $A$ and $B$ are constants independent of temperature. Since the sublimation pressure of $(+)$-catechin is very low (Table 2) and the mass loss rate below $423 \mathrm{~K}$ was undetectable using the existing micro balance, therefore, the Clausius-Clapeyron type expression for the sublimation pressure was introduced and the derivation of semi-empirical relation for the solid solubility becomes:

$T \ln \left(y_{1} P\right)=A^{\prime}+B^{\prime} \rho_{1}+C^{\prime} T$

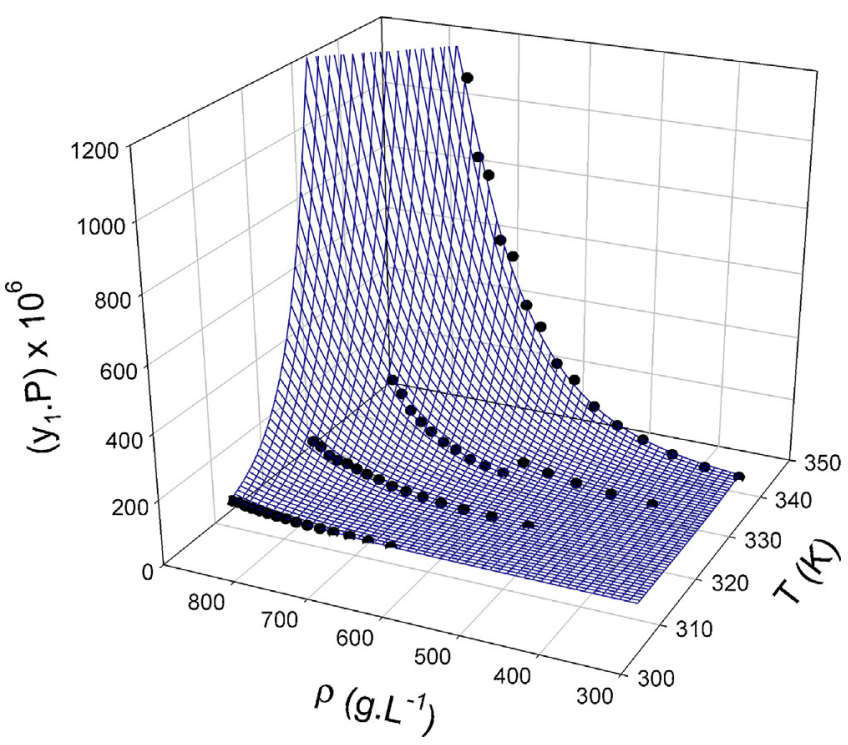

Fig. 10. Méndez-Santiago and Teja correlation (wire mesh) and experimental solubility data of (+)-catechin $(\bullet)$. where $A^{\prime}, B^{\prime}$ and $C^{\prime}$ are constants, which are independent of temperature and pressure. Fig. 10 shows the results of multivariable non-linear regression calculations. The obtained values of $A^{\prime}, B^{\prime}$ and $C^{\prime}$ are $-20818,3.650$ and 46.050 , respectively. The sum of squared errors (SSE) of this calculation is 0.145 . Based on the SSE, the semi-empirical density based equations were fitted very well to the experimental data of (+)-catechin solubility.

\section{Conclusion}

The solubility of (+)-catechin in $\mathrm{SC}-\mathrm{CO}_{2}$ with ethanol as the cosolvent was measured at several temperatures $(313.15,323.15$, 333.15 and $343.15 \mathrm{~K}$ ) and pressure in the range of $12-26 \mathrm{MPa}$. Semiempirical density based equations were found to fit the measured solubility data very well. (+)-Catechin is a stable phenolic compound with very low sublimation pressure.

\section{References}

[1] C. Garlapati, G. Madras, J. Chem. Eng. Data 53 (2008) 2913-2917.

[2] A. Braeuer, S. Dowy, A. Leipertz, R. Schatz, E. Schluecker, Opt. Express 15 (2007) 8377-8382.

[3] W.J. Schmitt, R.C. Reid, Fluid Phase Equilib. 32 (1986) 77-99.

[4] A. Berna, A. Chafer, J.B. Monton, S. Subirats, J. Supercrit. Fluids 20 (2001) $157-162$.

[5] A.R.C. Duarte, S. Santiago, H.C. de Sousa, C.M.M. Duarte, J. Chem. Eng. Data 50 (2005) 216-220.

[6] C. Garlapati, G. Madras, J. Chem. Eng. Data 53 (2008) 2637-2641.

[7] Z. Huang, W.D. Lu, S. Kawi, Y.C. Chiew, J. Chem. Eng. Data 49 (2004) 1323-1327.

[8] L.-H. Wang, Y.-Y. Cheng, J. Chem. Eng. Data 50 (2005) 1747-1749.

[9] S. Sang, X. Cheng, R.E. Stark, R.T. Rosen, C.S. Yang, C.-T. Ho, Bioorg. Med. Chem. 10 (2002) 2233-2237.

[10] S. Sang, S. Tian, H. Wang, R.E. Stark, R.T. Rosen, C.S. Yang, C.-T. Ho, Bioorg. Med. Chem. 11 (2003) 3371-3378.

[11] Y. Yilmaz, Food Sci. Technol.: LEB 17 (2006) 64-71.

[12] P. Lacopini, M. Baldi, P. Storchi, L. Sebastiani, J. Food Compost. Anal. 21 (2008) 589-598.

[13] M. Palma, Z. Pineiro, C.G. Barroso, J. Chromatogr. A 968 (2002) 1-6.

[14] C. Passos, R.M. Silva, F.A. Da Silva, M.A. Coimbra, C.M. Silva, Chem. Eng. J. 160 (2010) 634-640.

[15] Y. Yilmaz, E.B. Ozvural, H. Vural, J. Supercrit. Fluids 55 (2011) 924-928.

[16] I. Ramirez-Sanchez, L. Maya, G. Ceballos, F. Villarreal, J. Food Compost. Anal. 23 (2010) 790-793.

[17] S.M. Anthonysamy, N.B. Saari, K. Muhammad, F.A. Bakar, J. Food Biochem. 28 (2004) 91-99.

[18] C.-Y. Day, C.J. Chang, C.-Y. Chen, J. Chem. Eng. Data 41 (1996) 839-843.

[19] K. Suzuki, H. Sue, J. Chem. Eng. Data 35 (1990) 63-66.

[20] S.N. Joung, C.W. Yoo, H.Y. Shin, S.Y. Kim, K.-P. Yoo, C.S. Lee, W.S. Huh, Fluid Phase Equilib. 185 (2001) 219-230.

[21] S.E. Guigard, W.H. Stiver, Ind. Eng. Chem. Res. 37 (1998) 3786-3792.

[22] M. Skerget, Z. Knez, M. Knez-Hrncic, J. Chem. Eng. Data 56 (2011) 694-719.

[23] J. Chrastil, J. Phys. Chem. 86 (1982) 3016-3021.

[24] J.C. Gonzalez, M.R. Vieytes, A.M. Botana, J.M. Vieites, L.M. Botana, J. Chromatogr. A 910 (2001) 119.

[25] J. Mendez-Santiago, A.S. Teja, Fluid Phase Equilib. 158-160 (1999) 501-510.

[26] S.S. Pinto, H.P. Diogo, J. Chem. Thermodyn. 38 (2006) 1515-1522.

[27] W. Gückel, R. Kästel, T. Kröhl, A. Parg, Pest. Sci. 45 (1995) 27-31.

[28] D.M. Prince, S. Bashir, P.R. Derrick, Thermochim. Acta 327 (1999) 167-171.

[29] A. Lahde, J. Raula, J. Malm, E.I. Kauppinen, M. Karppinen, Thermochim. Acta 482 (2009) 17-20.

[30] J.P. Elder, J. Therm. Anal. 49 (1997) 897-905.

[31] A. Gairola, G.V. Kunte, A.M. Umarji, S.A. Shivashankar, Thermochim. Acta 488 (2009) 17-20.

[32] Y. Zuo, H. Chen, Y. Deng, Talanta 57 (2002) 307-316.

[33] R. Stryjek, J.H. Vera, Can. J. Chem. Eng. 64 (1986) 323-333.

[34] J.M. del Valle, J.M. Aguilera, Ind. Eng. Chem. Res. 27 (1988) 1551-1553.

[35] Y. Adachi, B.C.-Y. Lu, Fluid Phase Equilib. 14 (1983) 147-156.

[36] D.L. Sparks, L.A. Estevez, R. Hernandez, K. Barlow, T. French, J. Chem. Eng. Data 53 (2008) 407-410. 